\title{
A Comprehensive Model of a Doubly Fed Induction Generator for Dynamic Simulations and Power System Studies
}

\author{
J. Soens, J. Driesen , R. Belmans \\ Department of Electrical Engineering \\ ESAT/ELECTA, K.U.Leuven \\ Kasteelpark Arenberg 10, B-3001 Leuven (Belgium) \\ phone: +32 16 321031, fax: +3216321985 \\ e-mail: joris.soens@esat.kuleuven.ac.be
}

\begin{abstract}
The doubly fed induction generator (DFIG) is a very suitable generator type for wind turbine applications. However, its operation principles and its control are rather complex. This paper will describe the different steps for modelling and simulating the generator behaviour. A simulation example of the operation of a DFIG in a small power system is presented.
\end{abstract}

\section{Key words}

wind power generator, doubly fed induction generator, voltage support, machine simulation, power system simulation

\section{Introduction}

Wind power is an explosively expanding source of renewable energy in Europe: compared to 1995, the installed wind power in the European Union has been multiplied by almost a factor of ten. In some parts of Europe, such as northern Germany and Denmark, the installed wind power becomes a considerable fraction of the total installed system power. Therefore, wind power generators can no longer be fully excluded from the demands that are related to grid support: besides generating active power, wind turbines will also be required to provide some ancillary services, such as support for voltage and frequency control. As an illustration to this evolution, a reference can be made to the wind turbine connection requirements, issued by the German grid operator E.O.N., that came into effect on January $1^{\text {st }}, 2003[1]$.

Historically, the first wide-spread generator type for wind turbines was the induction generator. This generator has the advantage of being relatively cheap and robust. On the other hand, its speed cannot be continuously controlled, and it is a large and rather uncontrollable consumer of reactive power: this is a major disadvantage with respect to the grid voltage stability.
The doubly fed induction generator is a more suitable generator for wind turbines. It is constructed as an induction generator with wound rotor. The stator windings are directly connected to the grid. The rotor windings are connected to the grid through an IGBTfrequency converter. The frequency converter only has to process the generator's slip power fraction, which is generally no more than $30 \%$ of the generator rated power [2], [3], [4]. This reduced rating for the frequency converter implies an important cost saving, compared to a fully rated converter. A schematic diagram of a doubly fed generator is shown in Figure 1. To start up a machine from zero speed, an additional soft-starter connected to the stator windings may be needed.

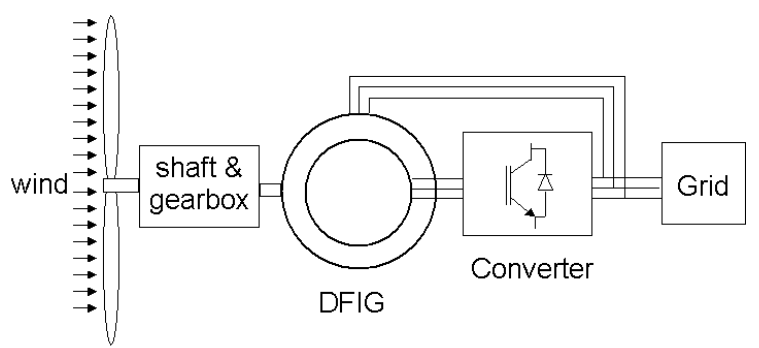

Fig. 1: Doubly fed induction generator

By means of controlling the rotor currents through the frequency converter, the speed and stator reactive power of the generator can be controlled in a small range around the generator's rated values. The extent of this range depends on the rating of the frequency converter. A rule of thumb is: if $P_{\text {conv }}=k \cdot P_{\text {stator, rated }}$, then the speed range limits are $(1 \pm k) \cdot n_{\text {rated }}$. Furthermore, the reactive power on the grid side of the converter can be controlled independently from the other machine parameters.

The modelling and control strategy of such a wind turbine doubly fed induction generator is the subject of this paper. 


\section{Model of the generator and its control}

\section{A. Model Structure}

The structure of the global model is depicted in Figure 2. The arrow directions indicate the data flow from and to the different submodels.

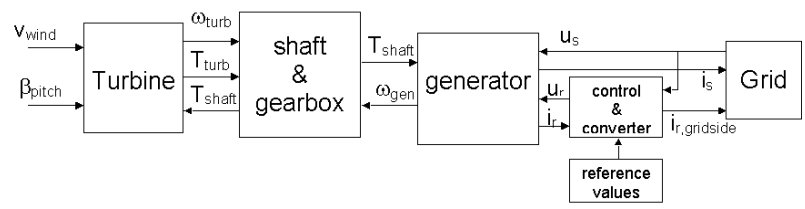

Fig. 2: Global overview of the model

The structure of the generator itself is depicted in Figure 3.

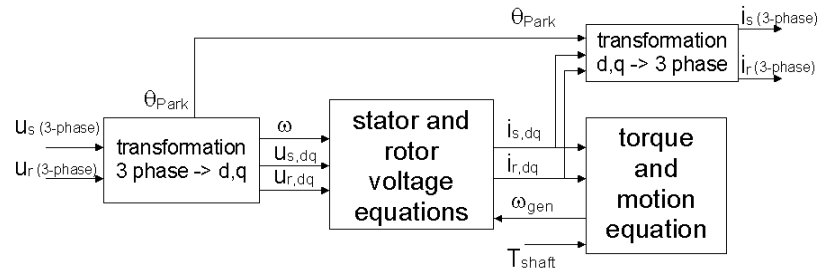

Fig. 3: Generator model structure

\section{B. Transformation towards $(d, q)$ - frame}

The 3-phase voltage is transformed into a voltage vector with d-q components, according to the well-known Park transformation. In a first step, the 3-phase voltage is transformed into a complex voltage vector, referred to a fixed $(\alpha, \beta)$-frame. The following transformation matrix is used:

$$
\left[\begin{array}{l}
u_{\alpha} \\
u_{\beta}
\end{array}\right]=\sqrt{\frac{2}{3}} \cdot\left[\begin{array}{rrr}
1 & -\frac{1}{2} & -\frac{1}{2} \\
0 & \frac{\sqrt{3}}{2} & -\frac{\sqrt{3}}{2}
\end{array}\right] \cdot\left[\begin{array}{l}
u_{a} \\
u_{b} \\
u_{c}
\end{array}\right]
$$

Various transformation matrixes can be used, who all differ in a constant factor. In (1), the choice has been made for a power invariant transformation. This means, when applying the same transformation matrix for both voltages and currents :

$$
P_{a b c}=u_{a} \cdot i_{a}+u_{b} \cdot i_{b}+u_{c} \cdot i_{c}=u_{\alpha} \cdot i_{\alpha}+u_{\beta} \cdot i_{\beta}=P_{\alpha \beta}
$$

In a second step, the coordinates of this voltage vector are referred to a rotating $(\mathrm{d}, \mathrm{q})$-frame, by a rotational transformation (3):

$$
\left[\begin{array}{l}
u_{d} \\
u_{q}
\end{array}\right]=\left[\begin{array}{cc}
\cos \theta & \sin \theta \\
-\sin \theta & \cos \theta
\end{array}\right] \cdot\left[\begin{array}{l}
u_{\alpha} \\
u_{\beta}
\end{array}\right]
$$

The usual approach is to align the d-axis with the rotor flux. This allows optimal decoupling between the d- and q-current control schemes, which is a important feature for high-performance speed controlled drives [5].

The approach in this paper is to align the (d,q)-frame as shown in Figure 4, i.e. aligned with the stator voltage. This implies that $u_{s, d}=0$ and $u_{s, q}=\left|\boldsymbol{u}_{s}\right|$. The rotor voltage is referred to the same frame, and consists in general of two non-zero $(\mathrm{d}, \mathrm{q})$-components.

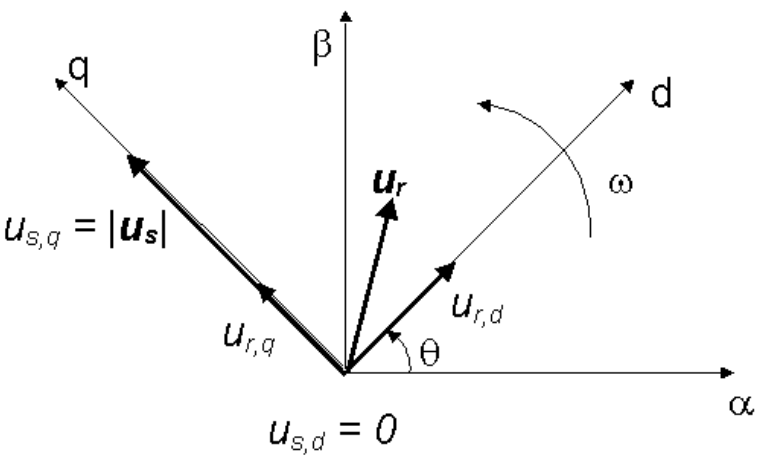

Fig 4: Choice of the (d,q)-frame orientation

This is a useful approach, particularly for doubly fed machines. The control is performed by means of the rotor voltage. The stator voltage is the grid voltage, and can be regarded as a 'disturbance factor'. In stable grid conditions, the grid voltage is approximately constant. As a result, with the chosen orientation the disturbance factor is zero in the d-axis and a DC-quantity in the qaxis. Another advantage of the chosen $(\mathrm{d}, \mathrm{q})$-frame orientation is that the expressions for stator active and reactive power simply become:

$$
p_{s}=u_{s q} \cdot i_{s q} \text { and } \quad q_{s}=u_{s q} \cdot i_{s d}
$$

It becomes clear that this is the most easy framework in which active and reactive power can be controlled independently.

In Fig. 3 it can be seen that the calculation of $\omega$ and $\theta$ (Park's angle) is done in the transformation block itself. In a rotor flux-oriented frame, $\omega$ and $\theta$ would have to be calculated in a flux-model, which is basically a reversed motor model that uses the measured machine currents as input.

The stator and rotor currents are calculated by the machine model, and can be transformed back into 3phase current by applying the inverse Park transformation.

It must be mentioned that many authors already noticed the importance of an appropiate choice for the reference frame. The use of the stator-flux oriented frame has also been suggested for a doubly fed machine (i.e. $\psi_{s, q}=0$ ) 
[4]. If the flux transients and the stator resistance are neglected, this is exactly the same frame as used here, as can be seen in the equations mentioned further (5), (6).

\section{The stator and rotor voltage equations}

The voltage equations for the stator and rotor are, in per unit notation and motor sign convention [6]:

$$
\begin{gathered}
u_{s, d}=r_{s} \cdot i_{s, d}-\frac{\omega}{\omega_{b}} \psi_{s, q}+\frac{1}{\omega_{b}} \cdot \frac{d}{d t} \psi_{s, d} \\
u_{s, q}=r_{s} \cdot i_{s, q}+\frac{\omega}{\omega_{b}} \psi_{s, d}+\frac{1}{\omega_{b}} \cdot \frac{d}{d t} \psi_{s, q} \\
u_{r, d}^{\prime}=r_{r}^{\prime} \cdot i_{r, d}^{\prime}-\left(\frac{\omega-\omega_{g e n}}{\omega_{b}}\right) \psi_{r, q}^{\prime}+\frac{1}{\omega_{b}} \cdot \frac{d}{d t} \psi_{r, d}^{\prime} \\
v_{r, q}^{\prime}=r_{r}^{\prime} \cdot i_{r, q}^{\prime}+\left(\frac{\omega-\omega_{g e n}}{\omega_{b}}\right) \psi_{r, d}^{\prime}+\frac{1}{\omega_{b}} \cdot \frac{d}{d t} \psi_{r, q}^{\prime}
\end{gathered}
$$

The motor sign convention implies that $i_{s, d(q)}$ is negative in case of power generation. As it is the most common formulation for general machine equations, the motor sign convention will be maintained here.

In these equations, $\omega$ is the rotational speed of the (d,q)frame (in rad/s). With the frame orientation chosen in $B$., $\omega$ is simply the instantaneous grid frequency $(\mathrm{rad} / \mathrm{s}) . \omega_{b}$ is a base value for the frequency, generally the system's nominal frequency. $\omega_{g e n}$ is the electrical speed of the rotor (rotational speed multiplied by pole-pair number).

The correlation between fluxes and currents is [6]:

$$
\begin{gathered}
\psi_{s, d(q)}=x_{s, d(q)} \cdot i_{s, d(q)}+x_{m, d(q)} \cdot i_{r, d(q)}^{\prime} \\
\psi_{r, d(q)}^{\prime}=x_{r, d(q)}^{\prime} \cdot i_{r, d(q)}^{\prime}+x_{m, d(q)} \cdot i_{s, d(q)}
\end{gathered}
$$

with $x_{s, d(q)}, x_{r, d(q)}^{\prime}$ and $x_{m, d(q)}$ respectively the stator, rotor and mutual inductance, in per unit notation and referred to stator quantities. Saturation can be modelled by making the inductances dependent on the flux level.

\section{Torque and motion equation}

The equation for the electromagnetic torque (per unit notation and motor sign convention) is:

$$
T_{e m}=i_{s, q} \cdot \psi_{s, d}-i_{s, d} \cdot \psi_{s, q}
$$

Several formulations for the torque in terms of fluxes and/or currents can be written. It is a disadvantage of the chosen reference frame that the torque equation will always consist of two non-zero terms. However, in this work, it is direct power control, and not direct torque control, that is the main target envisaged.

The mechanical motion equation is (motor sign convention):

$$
\frac{d}{d t} \omega_{\text {gen }}=\frac{1}{2 H_{\text {gen }}}\left(T_{e m}-T_{\text {shaft }}\right)
$$

Equations (5) to (12) are the entire machine model in $(\mathrm{d}, \mathrm{q})$-components.

\section{E. The stator current control}

In order to control the stator currents by modifying the rotor voltage, the reference values for the rotor currents that induce the desired stator currents need to be calculated with the following equation (applying for both d- and q-component).

$$
i_{r, d(q), r e f}=\frac{\psi_{s, d(q)}}{x_{m, d(q)}}-i_{s, d(q), r e f} \cdot \frac{x_{s, d(q)}}{x_{m, d(q)}}
$$

In reality, voltages and currents are the only electrical quantities that are measured, thus $\psi_{s, d}$ must be calculated from(9).

The rotor currents can be directly controlled from the rotor voltage. A P.I.-controller with limited output, for both $\mathrm{d}$ and q-components, is used (Figure 5). The P.I.controller is provided with anti-windup. This means that the input for the integrator is set to zero any time the output of the controller is not between its lower and higher limit value. Anti-windup prevents the integratorpart of the controller from building up too high output values, which would make the controller rather inert.

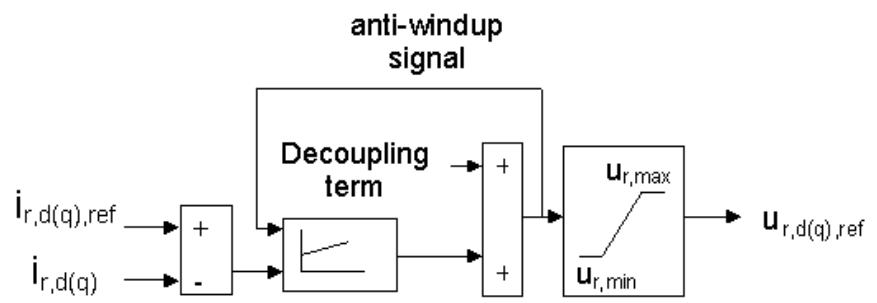

Fig. 5: Current P.I.-controller with decoupling and anti-windup

Decoupling terms are added to the output of the PIcontrollers to compensate for the influence from $\psi_{q, r}$ in the d-voltage equation and vice versa. It can be seen from equations (5) and (6) that the decoupling terms for the dand q-current controller are respectively:

$$
-\left(\frac{\omega-\omega_{g e n}}{\omega_{b}}\right) \psi_{q, r}^{\prime} \text { and }\left(\frac{\omega-\omega_{g e n}}{\omega_{b}}\right) \psi_{d, r}^{\prime}
$$

The converter builds up the real rotor voltage from the reference value. It can be modelled as a simple time delay. 


\section{F. Calculation of reference stator currents}

The reference values for $i_{s, d}$ comes from the reference reactive power. Alternatively, as reactive power is very strongly related to voltage control, a voltage controller could also directly provide a value for $i_{s, d, r e f}$. The reference value for $i_{s, q}$ is given either by the reference torque or by the reference active stator power (direct power control).

Either the machine speed or the machine active power can be controlled independently of the reactive power.

A speed-controlled doubly fed machine has possible applications for high-power precision drives that operate only around a narrow but continuous speed range around the synchronous speed, such as continuous rolling mills. The speed is controlled by a P.I.-controller with antiwindup. The output of that controller is a reference torque, which is then translated into a reference value for the stator q-current:

$$
i_{s, q, r e f}=\frac{T_{r e f}+i_{s, d} \cdot \psi_{s, q}}{\psi_{s, d}}
$$

The q-current behaviour is slightly influenced by a change in $i_{s, d}$ (or reactive power).

For variable speed generators, such as wind or hydro turbines, direct stator power control may be preferential: i.e. control directly stator active power output through the current with the following equation:

$$
i_{s, q, r e f}=\frac{p_{s, r e f}}{u_{s, q}}
$$

When the mechanical torque increases (due to a wind speed increase), the turbine will accelerate when the reference electrical power output remains the same. The turbine can thus act as a flywheel to store temporarily some excess energy and to damp out power output fluctuations due to wind speed changes. When the wind speed remains at a higher average level, either the reference electrical power must increase or the blades must be pitched out of the wind, to prevent too much acceleration.

The reactive power (seen from the grid) of the machine consists of two parts: rotor and stator reactive power. The grid-side rotor reactive power can be controlled by the frequency converter front-end, independent of the machine's operating point. However, as the rating of the converter's apparent power is limited (in order to save costs), the possibility to exploit the rotor converter as a kind of STATCOM is also limited.

More reactive power can be supplied or consumed by the stator windings. From equation (4), it can be seen that a reference value for the stator reactive power directly gives a reference value for $i_{s, d}$, which is used as the input for the d-current controller:

$$
i_{s, d, r e f}=\frac{q_{s, r e f}}{u_{s, q}}
$$

It is also possible to derive $i_{s, d \text {,ref }}$ from a reference voltage. A P.I.-controller uses then as input the voltage error on the controlled node (Figure 6). This controlled node can be the generator terminals, or another node nearby, as will be done further below.

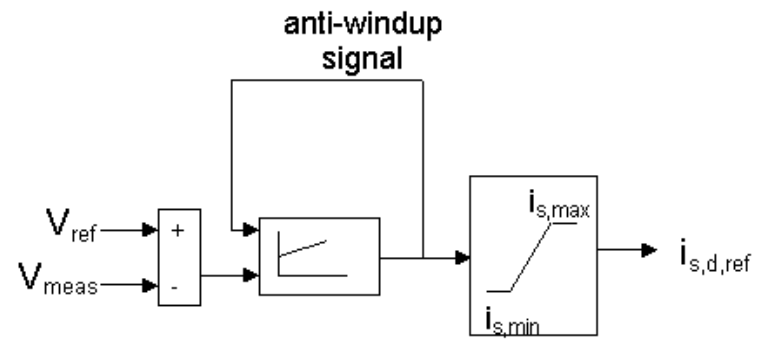

Fig. 6: Voltage control through reactive current control

\section{G. Rotor overcurrent relay}

The various controllers (for torque, reactive power and current) are equiped with limiters, which prevent the rotor reference current from becoming higher than the rated rotor current. But even then, it may occur that rotor currents become too high during a certain time. In case of a grid voltage dip, the stator currents will increase fast, and the rotor currents will increase too to compensate for the machine flux changes.

One way to protect the rotor converter from overcurrent is to bypass the converter with a 'crowbar', when the rotor current has been too high for a defined length of time. The converter is then put out of operation and the generator acts as a common induction generator with short-circuited rotor windings. The generator can be disconnected from the grid to wait for more stable grid conditions, or it can operate further as an induction generator. The way to protect the rotor converter accurately from rotor overcurrents, and at the same time operate the generator in such a mode that allows maximal grid support in any circumstances, has been the topic of many discussions that are not yet fully answered [7].

\section{Model of the mechanical torque}

The model structure for the mechanical torque of a wind turbine is depicted in Figure 2. The mechanical system is modeled as two rotating masses: the turbine and the generator, connected by a shaft with finite stiffness. 


\section{A. Turbine}

The mechanical power of a wind turbine is given by:

$$
P_{\text {turb }}=\frac{1}{2} \pi R^{2} \rho v_{\text {wind }}^{3} C_{p}\left(\lambda, \beta_{\text {pitch }}\right)
$$

in which $R[\mathrm{~m}]$ is the turbine radius, $\rho\left[\mathrm{kg} / \mathrm{m}^{3}\right]$ the air density, $v_{\text {wind }}[\mathrm{m} / \mathrm{s}]$ the wind speed, $\beta_{\text {pitch }}(\mathrm{deg})$ the pitch angle of the turbine blades, and $\lambda$ the tip-speed ratio, i.e.

$$
\lambda=\frac{\omega_{\text {turb }} R}{v_{\text {wind }}}
$$

$C_{p}$ is the wind energy capture efficiency, the fraction of the kinetic energy of the air that is captured as rotational energy by the turbine. $C_{p}$ is a rather complex function of the wind speed and its division over the rotor surface area, and of the turbine speed and pitch angle. $C_{p}$ can be calculated by e.g. the 'Blade Elementum Method'. The numerical approximation that is used in this simplified mechanical model is given by equations (20) and (21), of which a plot is given in Figure 7 [4]:

$$
\begin{aligned}
C_{p}\left(\lambda, \beta_{\text {pitch }}\right) & =0.22\left(\frac{116}{\lambda_{i}}-0.4 \beta_{\text {pitch }}-5\right) \cdot e^{\frac{-22.5}{\lambda_{i}}} \\
\text { with } \frac{1}{\lambda_{i}} & =\frac{1}{\lambda+0.08 \cdot \beta_{\text {pitch }}}-\frac{0.035}{\beta_{\text {pitch }}^{3}+1}
\end{aligned}
$$

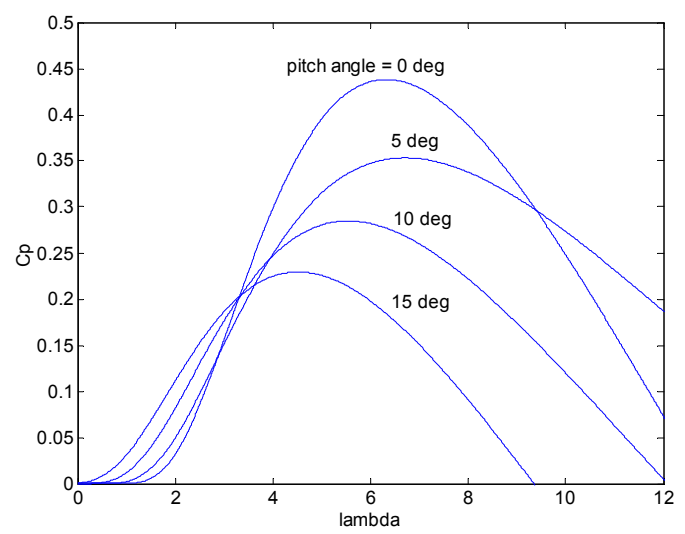

Fig. 7: Approximation for $C_{p}\left(\lambda, \beta_{\text {pitch }}\right)$

The plot in Figure 7 show that for each pitch angle there is a value for $\lambda$ at which $C_{p}$ becomes maximal. This corresponds with the optimal turbine speed for a given wind speed.

From (18), it follows that the mechanical turbine torque is equal to:

$$
T_{\text {turb }}=\frac{1}{2} \pi R^{3} \rho v_{\text {wind }}{ }^{2} \frac{C_{p}\left(\lambda, \beta_{\text {pitch }}\right)}{\lambda}
$$

The turbine motion equation calculates the turbine speed:

$$
\frac{d}{d t} \omega_{\text {turb }}=\frac{1}{2 H_{\text {turb }}}\left(T_{\text {turb }}-T_{\text {shaft }}\right)
$$

\section{B. Shaft (and gearbox)}

The shaft and gearbox are together represented as a torsion spring and damper [3], [8]. The gearbox ratio is included in the base values that are used to transform real quantities into per-unit values. It is thus not explicitly apparent in the model of the shaft. The equation to calculate $T_{\text {shaft }}$, which will be used as input for the generator model, is:

$$
\begin{aligned}
& T_{\text {shaft }}=K_{\text {shaft }} \cdot\left(\alpha_{\text {turb }}-\alpha_{\text {gen }}\right)+C_{\text {shaft }} \cdot\left(\omega_{\text {turb }}-\omega_{\text {gen }}\right) \\
& \text { in which } \alpha_{\text {turb }}=\int \omega_{\text {turb }} d t \text { and } \alpha_{\text {gen }}=\int \omega_{\text {gen }} d t
\end{aligned}
$$

\section{Use in power system simulations}

\section{A. Simulation grid}

The above equations allow to assemble a model of a controlled doubly fed induction generator in any software environment. When a power system simulation tool is used, which allows the use of self-defined machine models, then the above described model of a wind turbine generator can be used to evaluate the capabilities of the generator to perform voltage control in a local grid. Furthermore the impact from a grid disturbance on the turbine can be simulated.

The power system simulation tool Eurostag [9] is used to this purpose. The demo grid (Figure 8) consists of 7 buses on $30 \mathrm{kV}$-level, of which one node (' $S L A C K$ ') is an infinite node. The wind turbine generator is modeled as a (IR,II)-injector, connected to a $690 \mathrm{~V}$-node ('TURB'). Its nominal power is $2 \mathrm{MW}$. The electrical data are given in TABLE I and are typical data for a $2 \mathrm{MW}$-sized turbine. The initial loads at each node are given in TABLE II. The load at BUS6 is modelled as an induction motor. For all lines, $\mathrm{R}_{\text {line }}=0.01$ p.u. and $\mathrm{X}_{\text {line }}=0.05$ p.u. A high $\mathrm{X} / \mathrm{R}$ ratio for the lines allows voltage control by means of reactive power control. 


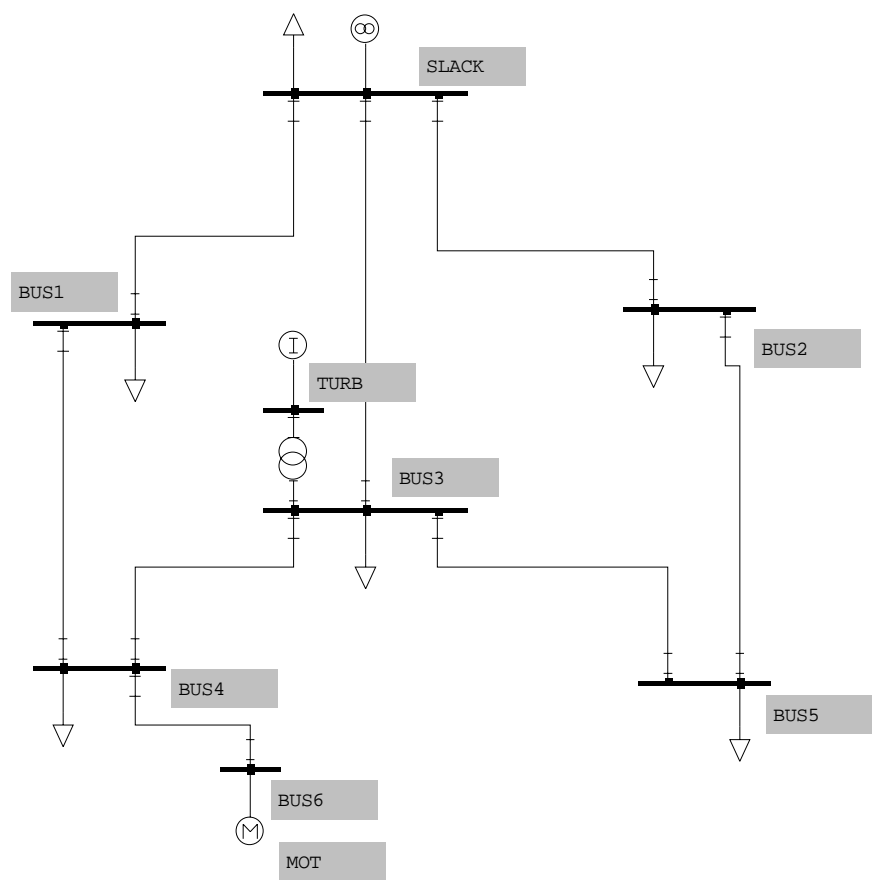

Fig 8: Demo grid

TABLE I Generator and turbine data

\begin{tabular}{|c|c|c|c|}
\hline $\mathrm{r}_{\mathrm{s}}$ [p.u.] & 0.0105 & $\mathrm{H}_{\text {gen }}[\mathrm{s}]$ & $0.5 \mathrm{~s}$ \\
\hline $\mathrm{r}_{\mathrm{r}}$ [p.u.] & 0.0130 & pole pairs: & 2 \\
\hline $\mathrm{x}_{\mathrm{m}, \mathrm{d}}$ [p.u.] & 4.37 & gearbox & $1: 88$ \\
\hline $\mathrm{x}_{\mathrm{m}, \mathrm{q}}$ [p.u.] & 4.37 & $\mathrm{R}_{\text {turb }}$ & $38 \mathrm{~m}$ \\
\hline $\mathrm{x}_{\mathrm{s}, \mathrm{d}}$ [p.u.] & 4.55 & $\mathrm{H}_{\text {turb }}$ & $500 \mathrm{~s}$ \\
\hline $\mathrm{x}_{\mathrm{s}, \mathrm{q}}$ [p.u.] & 4.55 & & \\
\hline
\end{tabular}

TABLE II Initial loads in the demo grid

\begin{tabular}{|c|c|c|}
\hline BUS & Active Load & Reactive Load \\
\hline & [MW] & [MVAr] \\
\hline Bus1 & 0.5 & 0.4 \\
\hline Bus2 & 1.0 & -0.1 \\
\hline Bus3 & 1.0 & 0.0 \\
\hline Bus4 & 0.6 & 0.5 \\
\hline Bus5 & 4.0 & -0.2 \\
\hline Bus6 & 3.0 & 1.0 \\
\hline
\end{tabular}

\section{B. Simulated cases}

Three cases were simulated, depending on the type of wind turbine generator:

1) induction generator (short circuited rotor windings)

2) doubly fed induction generator, stator reactive power controlled to be zero at its $690 \mathrm{~V}$ terminals

3) doubly fed induction generator, stator reactive current controlled to maintain the voltage of BUS3 at 1 p.u.
In each case, the rotor grid-side reactive power was zero. The rotor active power is exchanged with the grid (both generation and consumption are possible).

For each of the three cases, the turbine is in steady-state operation at the start of the simulation. Then, some variations in wind speed are simulated: $v_{\text {wind }}$ fluctuates randomly between $7 \mathrm{~m} / \mathrm{s}$ and $15 \mathrm{~m} / \mathrm{s}$, from $\mathrm{t}=100 \mathrm{~s}$ until $\mathrm{t}=250 \mathrm{~s}$. The reference active stator power in cases 2) and 3) remains $1 \mathrm{MW}$ all the time. The electrical output of the induction generator cannot be continuously controlled.

From $t=250$ s, the wind speed is kept constant, to be able to view more clearly the impact of variations of the active and reactive load at various nodes. The following load variations are simulated:

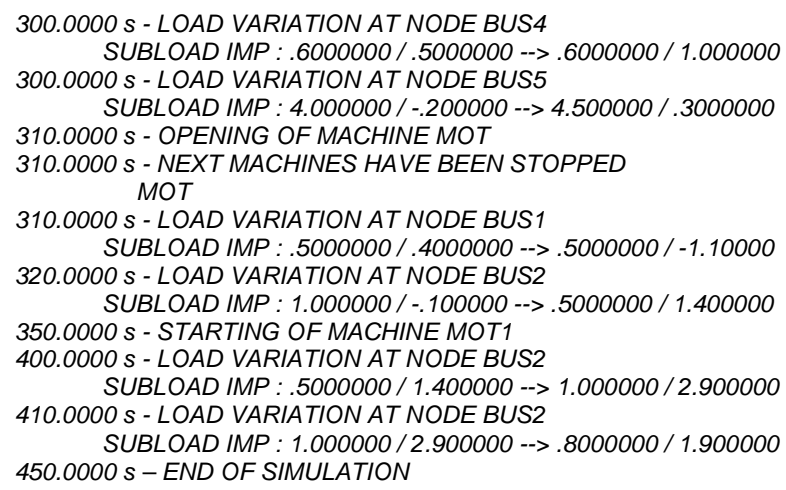

The voltage at BUS3 is shown in Figure 10. There is a clear difference in voltage behaviour between the three cases:

The use of an induction generator implicates the worst voltage behaviour. At a change of wind speed (and thus generator torque), both active and reactive power of the induction machine change. Especially the reactive power fluctuations cause high voltage fluctuations in a grid with inductive lines.

The impact of wind speed fluctuations on the voltage is much lower when a doubly fed induction generator is used that consumes no reactive power. However, when the grid voltage changes due to load changes, the generator does not control the voltage at its terminals.

When the reference value for $i_{s, d}$ is calculated by a voltage controller, the voltage at the generator terminals or at another node (in this case: BUS3) can be controlled.

The reactive power consumption of the turbine is shown in Figure 10. It is seen that the voltage-controlled turbine can operate in both the inductive and capacitive region. At $\mathrm{t}=350 \mathrm{~s}$ and also at $\mathrm{t}=400 \mathrm{~s}$ until $\mathrm{t}=410 \mathrm{~s}$, the generator delivers its maximum reactive power, as $i_{d, s}$ is limited. Therefore the voltage can no longer be maintained at 1 p.u. during that time, as is seen on Figure 9. 


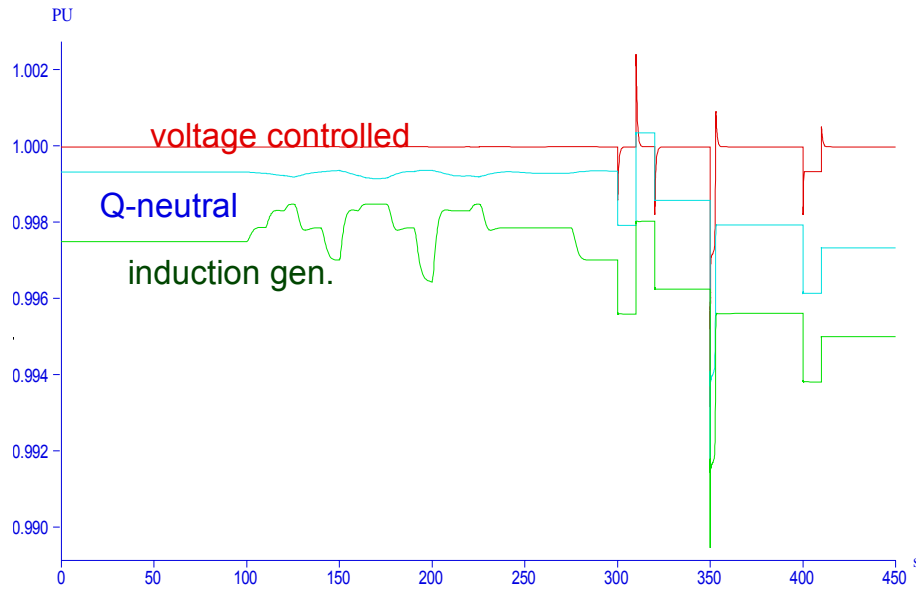

Fig 9: Voltage [p.u.] at BUS3 for three simulated cases

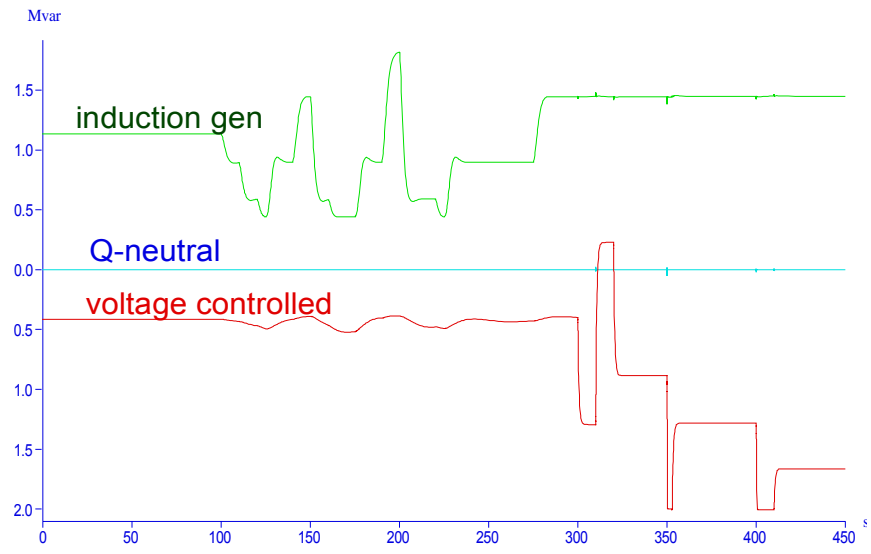

Fig 10: Stator reactive power consumption [MVAr] for three simulated cases

\section{Conclusions}

This paper has outlined the model of a controlled doubly fed induction generator, with a simplified mechanical model of the wind turbine. The model includes an accurate generator model without neglecting any transient electrical terms. Furthermore a simplified model of the mechanical turbine and shaft is given. The active and reactive power of the generator can be controlled independently.

The given equations allow to build the model in any programming language.

The model is used here in a power system simulation tool, EUROSTAG, to show its voltage control capabilities within a limited range.

\section{Acknowledgements}

The authors are grateful to the Belgian 'Fonds voor Wetenschappelijk Onderzoek Vlaanderen' for their financial support of this work. J. Soens is a doctoral research assistant of the F.W.O.-Vlaanderen. J. Driesen holds a postdoctoral research fellowship of the Belgian "Fonds voor Wetenschappelijk Onderzoek - Vlaanderen".

\section{References}

[1] Ergänzende Netzanschlussregeln für Windenergieanlagen, E.O.N., December 2001,

http://www.eon-netz.com/

[2] Müller, M. Deicke, R. W. De Doncker, 'Adjustable Speed Generators for Wind Turbines based on Doublyfed Induction Machines and 4-Quadrant IGBT Converters Linked to the Rotor,' 2000 IEEE Industry Applications Society Annual Meeting, Oct. 08-Oct. 12, 2000, paper 51-02.

[3] V. Akhmatov, 'Modelling of Variable-Speed Wind Turbines with Doubly-Fed Induction Generators in ShortTerm Stability Analysis', Proceedings of the $3^{\text {rd }}$ International Workshop on Transmission Networks for Off-shore Wind Farms, Stockholm, April 11-12, 2002.

[4] Slootweg J.G., H. Polinder, W.L. Kling; 'Dynamic modelling of a wind turbine with doubly fed induction generator'. Proceedings. 2001 IEEE Power Engineering Society Summer Meeting (Vancouver, 15-19 July 2001), IEEE Power Engineering Society, S.1., 2001, p. 1-6.

[5] D.W.Novotny, T.A. Lipo, 'Vector Control and Dynamics of AC Drives', Oxford University Press (1996) pp226-247

[6] P.C. Krause. O. Wasynczuk, S.D. Sudhoff, 'Analysis of Electric Machinery’, IEEE Press, New Yerk, 1995, pp. $172-175$

[7] Slootweg, J.G., De Vries, E., 'Problematiek kortsluitgedrag windturbines onderschat', Energietechniek 7/8, jrg. 80, juli/augustus 2002, pp. 3236. (in Dutch)

[8] H.Ø. Røstøen, T.M. Undeland, T. Gjengedal, 'Doubly fed induction generator in a wind turbine', Proceedings of wind power and the impacts on power systems workshop, Oslo 2002

http://www.elkraft.ntnu.no/eno/Papers2002/Rostoen.pdf

[9] http://www.eurostag.be/ 